is clearly one of expediency. If it promotes better co-operation and does not undertake functions which existing public or private agencies can perform, it is justified if the work it undertakes is necessary.

Those who are asked to support an organization should determine, if possible, if it will perform a useful service which no other organization can or will undertake, and they should be sufficiently interested in its objects to devote the necessary time and money to support its work, and not merely lend their names.

The recent tendency toward greater co-operation among groups should be encouraged in the hope that gradually greater concentration upon the problems of modern society may be made possible. That there is such a tendency towards greater co-operation is evidenced by the formation of federations, councils, and conferences. There have been many instances in which two or more organizations have co-operated to carry on special activities. Consolidations have been urged for the purpose of unification of effort in such fields as that of the public health, and in other activities consolidations have been effected.

The remarkable growth of public opinion and of democracy are the amazement of the last half century. Never before has the average man been as interested as he is to-day in questions affecting the life of the community. But this interest is likely to lead many far afield and away from the straight and narrow way unless it is directed and concentrated upon fundamental questions. If, however, the attention of an enlightened people can be focused and concentrated upon those problems which affect the life and labor of the nation, and upon the relations between nation and nation throughout the world, democracy will be rescued from one of its greatest dangers, which comes from the confusion caused by the complexity of modern life, which co-operation and organization may diminish, but which is increased by a multitude of organizations.

\title{
THE SUPPRESSION OF THE SMOKE NUISANCE
}

\author{
BY E. P. ROBERTS 1 \\ Cleveland
}

$Y^{\circ}$ OUR question as to what in my judgment "have been the more important developments along the line of the suppression of the smoke nuisance in cities" is difficult to answer because, in my opinion, smoke abatement is being obtained not by one or more pre-

${ }^{1} \mathrm{Mr}$. Roberts, who is a consulting engineer, was commissioner of smoke abatement in Cleveland, Ohio, from 1913 to 1914. Prior to which he was Chairman of the Cleveland chamber of commerce committee on smoke abatment. $\mathrm{He}$ is a member of the American society of mechanical engineers and also of the Institute of electrical engineers, and of the American electrical railway association and past president of the Cleveland engineering society. 
ponderatingly important developments, but the application of engineering design to each case, rather than special invention; and adequate construction followed by correct operation, and "public demand" being the force which has caused such activities.

Some of the lines of recent development have been as follows:

First: Ascertaining dumage caused by smoke, and informing the public as to same.

Second: Increasing realization of the fact that smoke abatement is an engineering problem.

Third: An increasing appreciation by those who design fuel combustion plants in which bituminous coal is to be used, as to the necessity, if complete combustion and practically smokeless operation is to be obtained, of adequate draft (not only at the stack but also at the grates), a large combustion chamber at high temperature, adequate flame travel, and, especially for hand firing, arches, piers or other structures, to deflect and mix the gases and air.

Fourth: Increasing use of automatic stokers properly set. In cities where, to some extent, smoke abatement has been obtained, it is becoming appreciated that no apparatus is "fool proof" and that the general design must be correct and based on consideration of the character of coal and the character of service. A recent government bulletin makes a statement to the effect that a poor stoker properly set is better than a good stoker improperly set, from which it may be inferred that the general engineering design is more important than the specific apparatus.

Fifth: In connection with steam locomotive operation, the development of an underfeed stoker. In connection with locomotives in roundhouses, the development of a washing process, and the use of a house steam line for blowers and jets.

Sixth: In connection with bituminous coal as fuel for metallurgical purposes, the development of the use of powdered fuel.

\section{NOTES RELATIVE TO EACH OF THE ABOVE STATEMENTS}

First: To obtain smoke abatement there must be a sustained public demand.

To obtain and maintain public demand each individual must be informed as to the damage to the community and especially to him, which results from smoke.

So to inform the public, requires that some organization of local standing investigate and report, and to maintain the demand requires that such organization maintain its activity, ascertain what is and is not being done and why, the methods and efficiency of the city smoke abatement department, the reasonableness of its rules, regulations and procedure, and the decisions of the court. A "well informed" demand is necessary; it is too much to expect that the public will be "well informed," 
but those who create and maintain the demand should be of such standing that the public will have confidence in their statements.

The Cleveland Chamber of Commerce committee on smoke abatement in 1909 was helpful as to informing the public as to the loss from smoke. The recent bulletins issued by the University of Pittsburgh, as the result of a $\$ 40,000$ investigation, are a striking example of obtaining and furnishing information.

The Chicago smoke inspector's reports have been helpful in Chicago and elsewhere. Possibly, especially in Chicago, they would have carried less weight if the statements and the work of the department had not received the backing of a strong commission, headed by an unusually active and well-known business man, and also if the public had not known that such was the fact.

A "demand" for smoke abatement may make it a live subject for the newspapers. And therefore free and, perhaps, favorable advertising become available. As a result of the cumulative effect, of public demand, civic organizations representations and newspaper comment the administration "sees its way" to provide at least approximately sufficient funds for the purpose, and is likely to decide that, from every standpoint, it is a wise expenditure and will not be adversely criticised. In addition such legal action as is necessary is obtainable, including legislative and disciplinary action. In a talk before the Cleveland Chamber of Industry November 10, 1914, I stated:

"What the community wants, demands and keeps on demanding, is what it will get from its city servants, and is also what its city servants can give it. This applies to the administration, the council, the subordinate executive offices, and, possibly, to the courts."

Second: Increasing realization of the fact that smoke abatement is an engineering problem.

To obtain results, engineers, observers and a clerical force are necessary. The chief should be a competent engineer of personal and professional standing. A competent engineer requires not only a reasonable salary, but also, of equal, if not greater, importance, such conditions as will enable him to obtain results. The public, or one or more civic organizations, or a commission, must not only obtain the demand, but also keep in touch with the facts, give publicity to same and maintain it. Self consciousness of duty performed is important; but recognition of such fact is desirable, and may be vital to success. Adverse criticism is to be expected; but the public should be well informed as to the facts by those whom they will not consider partial. It is difficult for the chief to preserve his enthusiasm and to maintain enthusiasm in his subordinates unless work well done is so recognized.

Third: An increasing appreciation by those who design fuel combustion plants in which bituminous coal will be used, as to the necessity, if 
complete combustion and practically smokeless operation are to be obtained, of adequate draft (not only at the stack, but also at the grates), a combustion chamber at high temperature, adequate flame travel, and, especially for hand firing, arches, piers or other structures, to deflect and mix the gases and air.

Although certain general principles must, as in all engineering work, be applied, nevertheless, if the best results are to be obtained, each case is a special study. Theoretically the offender should obtain his own advisor; but practically there are few specialists on smoke abatement and, therefore, all smoke inspection or abatement offices must, to a considerable degree, act as advisory engineers. Advice cannot be given until the conditions are investigated and to do so requires time. Merely noting violations and arresting offenders has not and, for some time to come, will not prove satisfactory. Abatement by prevention, due to requiring proper design of new plants and assistance in redesigning existing plants, and advice as to operation will bring results. In some cases legal action is necessary, in order to force reconstruction and proper care, and the result of such action should discourage the continuance of smoke not only on the part of the offender but also by others. During 1912-'14 (mainly '13-'14) the new and reconstructed boiler plants in Cleveland totaled 676 boilers $-95,729$ h. p. Few of these plants violate the smoke ordinance often, if at all.

Fourth: Increasing use of automatic stokers properly set. In cities where, to some extent, smoke abatement has been obtained it is becoming appreciated that no apparatus is "fool proof" and that the general design must be correct and based on consideration of the character of coal and the character of service.

A good fireman is essential, but the means furnished to him should be proper for the purpose.

In a general way no patented apparatus is necessary, but sometimes apparatus which is patented may be helpful, if it is chosen with reference to the character of the coal, rate of combustion, degree of variableness of load, etc. What is very satisfactory in one case may be a failure in another. There is probably no condition for which to obtain the best results, competition between manufacturers of the same class of apparatus is not obtainable.

Some stokers and boilers make a better combination than others, not because of being better individual units, but because they can be better set relative to each other, or better "hitched" together to make a balanced team. Stokers are advisable for any boiler exceeding $150 \mathrm{~h}$. p. There must be team work and a competent driver. A good driver may get more out of a poor team than will a poor driver out of a good team. It is advisable that both be good.

Fifth: In connection with steam locomotive operation, the develop- 
ment of an underfeed stoker. In connection with locomotives in roundhouses the development of a washing process. Improvement of locomotive operation in Cleveland has resulted from better equipment (arches, jets and blowers and a few stokers), better instruction and supervision, and stricter discipline.

The following shows the percentage of smoke during six months' periods in Cleveland. As several thousands readings were taken the percentages are approximately correct and properly indicate comparative results, as each locomotive seen by the observer is recorded.

Average Per Cent No. of Readinga

Second half 1912, 6.7, Ringelmann chart basis, 463

$\begin{array}{llllll}\text { First } & \text { " } 1913,4.3, & \text { " } & \text { " } & 1,566 \\ \text { Second } & \text { " } 1913,3.5, & \text { " } & \text { " } & \text { " } & 2,022 \\ \text { First } & \text { " } 1914,1.6, & \text { " } & \text { " } & \text { " } & 2,190 \\ \text { Second } & 1914,1.4, & \text { " } & \text { " } & \text { " } & 2,479\end{array}$

An underfeed stoker is, I believe, the only locomotive stoker yet developed which is successful from the smoke standpoint.

The round-house proposition is a very difficult one. Considerable improvement in Cleveland has resulted from the use of semi-bituminous coal or coke for starting fires the use of house steamline for blower, and one road is now using its standard steam jets obtaining steam from the house line (suggested by the writer), which has proved very helpful. At present, in my opinion, the most successful, from the smoke standpoint, is a washing process, such as used by the L. S. \& M. S. R. R. at Chicago.

Sixth: In connection with bituminous coal as fuel for metallurgical purposes, the development of the use of powdered fuel and certain types of stokers.

Many metallurgical furnaces present very difficult features, both in fact and because of the natural opposition of the men to any change which, they fear, may affect the output, as usually they work on a tonnage basis.

Smokeless operation, using bituminous coal, requires excess air. Many processes require a reducing flame, necessitating deficiency of air. Secondary combustion beyond the reducing section is difficult to obtain. The inertia on the part of owners and men is great. I expect in the near future considerable improvement without recourse to new apparatus or special fuel. For some purposes and in plants using considerable fuel, powdered coal has proved successful. The greater use of gas is to be expected. The development of electrical precipitation of all suspended matter in gases probably has a future, especially for certain classes of fuel combustion plants.

In conclusion-Smoke Abatement is a subject in which I am deeply interested and I thank you for giving me an opportunity to make a few 
statements relative thereto. As Chairman of the Cleveland Chamber of Commerce Committee on Smoke Abatement for several years prior to 1912 , my interest in smoke abatement commenced long before I became officially connected with the work, and has not ceased now that I have returned to my work as a consulting engineer. During a recent visit to one of the larger cities in the south I noticed an invitation by the chamber of commerce "Add to our Smoke Stacks." I filed a protest.

\title{
THE NEW YORK CONSTITUTIONAL CONVENTION
}

\author{
BY CHARLES A. BEARD \\ New York
}

I

$\mathbf{I}^{\mathrm{T}}$

T CAN hardly be said that the New York convention of 1915 was the product of a crying demand for constitutional revision. If the vote on the referendum calling for a new constituent assembly is to be taken as a just measure of popular interest, the overwhelming majority of the people were indifferent about the matter. It is true that there was a decided improvement in the popular vote on candidates for membership in the convention, but that may be taken as representing the normal enlargement of the vote which results from the work of party organizations and the general interest in personalities as contrasted with measures. All in all, the people of New York were reasonably satisfied with the frame of government established by the convention of 1894, and the calling of a new constituent assembly was in the main the work of partisan leaders.

Normally, the question of calling a convention would not have been submitted until 1916, but the Democrats, overcome by a false sense of security, after the Republican collapse of 1912, decided that the time was ripe to repay the Republicans for their gerrymander of 1894 and to write a constitution of their own. Accordingly, they advanced the date of submitting the question, threw the weight of the party organization in favor of it, and carried the day by a painfully small margin-the legality of which was seriously questioned. Then, to their deep chagrin, the Republicans showed a surprising resiliency and sprang back into power with an astounding vigor, electing an overwhelming majority of the delegates-116 Republicans to 52 Democrats. Moreover, it was the conservative wing of the party that was returned to power-the group represented by Mr. Root, Mr. Barnes, Mr. Wickersham, Mr. Stimson, and other leaders who had taken a decided stand against the "progressive" tendencies of 1912 . In other words, according to all outward signs, the 